\title{
Influence of toxic metal exposure on the gut microbiota (Review)
}

\author{
FEDERICA GIAMBÒ $^{1}$, SEBASTIANO ITALIA ${ }^{1}$, MICHELE TEODORO ${ }^{1}$, GIUSI BRIGUGLIO ${ }^{1}$, \\ NICOLA FURNARI $^{1}$, ROSARIA CATANOSO ${ }^{1}$, CHIARA COSTA $^{2}$ and CONCETTINA FENGA ${ }^{1}$ \\ ${ }^{1}$ Department of Biomedical and Dental Sciences and Morphofunctional Imaging, Occupational Medicine Section, \\ and ${ }^{2}$ Department of Clinical and Experimental Medicine, University of Messina, I-98125 Messina, Italy
}

Received November 17, 2020; Accepted January 25, 2021

DOI: $10.3892 /$ wasj.2021.90

\begin{abstract}
The gut microbiota (GM) is composed of $>100$ trillion different organisms, including bacteria, viruses, fungi, archaea and protists, coexisting in a complex system. The GM can be very sensitive to drugs, diet or even environmental pollutants. In the present review, recent data related to the interaction between the GM and heavy/toxic metals are discussed, focusing on the compounds most widely distributed in the environment or considered biopersistent. There are data to suggest that exposure to metals can alter the composition, diversity, homogeneity and structure of the GM. The specific modifications reported are not homogeneous, and a number of factors may explain this variability, including differences in metal compound, exposure modalities (e.g., food, water, in vitro), exposure time, qualitative and quantitative diversity of bacterial species in basal microbiota and analytical issues. As regards metal nanoparticles, some authors foresee the premises for a safe preventive and therapeutic use, while others have revealed harmful effects on both the gut microbiome and health. These findings, which would benefit from the application of modern approaches such as metagenomic sequencing and metabolomics, seem to indicate structural and functional analysis of gut microbiota as an early biomarker of detrimental effects from exposure to metals.
\end{abstract}

\section{Contents}

1. Introduction

2. Data collection and analysis

3. Overview

4. Arsenic

5. Cadmium

Correspondence to: Professor Chiara Costa, Department of Clinical and Experimental Medicine, University of Messina, Policlinico Universitario 'G. Martino'-pad. H, Via Consolare Valeria 1, I-98125 Messina, Italy

E-mail:ccosta@unime.it

Key words: microbiota, heavy metals, environmental and occupational exposure, nanoparticles
6. Mercury
7. Lead
8. Zinc
9. Copper
10. Nanoparticles
11. Other heavy metals
12. Conclusion

\section{Introduction}

The human intestinal microbiota is a topic of great interest for its fundamental role in several aspects of host homeostasis, such as nutrition, immune development, metabolism and defense against pathogens (1). The gut microbiota (GM) is estimated to be composed of $>10^{14}$ microorganisms: It is represented by a complex system of bacteria, archaea, viruses and fungi who live in symbiosis with the host (2). The individual pattern changes over the years and it is subjected to strong variations due to environmental changes, diet, exposure to antigens, infections, drugs, hygiene factors and lifestyle (3). Several studies have assessed the association between environmental stressors and GM integrity. The interaction between the host and microbiota determines the difference between eubiosis and dysbiosis. This balance can be altered by air pollution, exposure to pesticides and heavy metals, and can promote the development of diseases, such as obesity, type 2 diabetes mellitus, metabolic diseases and cancer (4-8).

Toxicants in the environment can directly harm the components of the microbiota, but can also be modified by the microbiota to become more or less toxic to the host and/or the microbiota itself (3). The effects of heavy metals on the intestinal microbiota are not still largely defined (Fig. 1).

The aim of the present review was to provide an update of the available evidence in the literature related to the interaction between the GM and heavy metals, focusing on the compounds most widely distributed in the environment or considered biopersistent.

\section{Data collection and analysis}

A literature search was performed on the PubMed database to detect full-text articles published over the past 5 years using the following keywords: 'Gut microbiota AND heavy metals' [All fields], 'gut microbiota AND arsenic' [All fields], 
'gut microbiota AND cadmium' [All fields], 'gut microbiota AND copper' [All fields], 'gut microbiota AND manganese' [All fields], 'gut microbiota AND chromium' [All fields], 'gut microbiota AND nickel' [All fields], 'gut microbiota AND mercury' [All fields], 'gut microbiota AND zinc' [All fields], 'gut microbiota AND lead exposure' [All fields]. Articles published in languages other than English, reviews or conference abstracts or letters to editors were not included.

The search produced a total of 610 results. As much as 455 articles were not pertinent with the aims of the present review and after excluding 58 repeated results, a final number of 97 articles was selected for the review. Additionally, supplementary articles were identified among the reference list of the screened articles.

\section{Overview}

Human GM. The human microbiota is the set of symbiotic microorganisms that coexist in the human body; it is composed of $>100$ trillion different organisms in a complex system of bacteria and viruses, as well as fungi, archaea and protists (2). In the majority of studies, the bacterial constituents of a microbial population were identified by sequencing the 16 sRNA-encoding gene. GM varies among individuals during development, and is dependent on the host and environmental factors (9). This gut microbial community has evolved with its host over a timespan of millions of years and offers benefits to its host through a number of mechanisms, including digestion, detoxification, the production of nutrients, protection against pathogens and the regulation of the immune system (10). The intestinal tract is exposed to a plethora of food-borne and bacterial antigens. The epithelial cell layer prevents a 'too close contact' of these antigens with the immune cells, and thereby also protects the gut from unwanted immune reactions. This is achieved by the sophisticated organization of the intestinal epithelium, which establishes a tightly regulated barrier (11). In adults, the GM is composed of 500 species of bacteria divided into 45 genera and 14 families; however, the individual pattern changes over the years and it is subjected to strong variations due to environmental changes, diet, exposure to antigens, infections, drugs, hygiene factors and lifestyle. The most frequent microorganisms are commensal bacteria that are beneficial for the host.

The analysis of normal bacterial communities has indicated that the enteric microbiota in healthy subjects belongs mainly to 4 phyla: Firmicutes and Bacteroidetes that are the most representative (together they represent $90 \%$ of total enteric microbiota), Proteobacteria and Actinobacteria (including Bifidobacterium), which are mainly driven by dietary intake, but are independent of age or body mass index (12). Fusobacteria, Cyanobacteria and Verrucomicrobia are less represented.

Heavy metals. Heavy metals are naturally occurring elements that have a high atomic weight and density. Both prokaryotes and eukaryotes have developed strategies to benefit their action and to defend themselves from undue exposure, particularly against those metals showing high reactivity. These metals are commonly spread and many of them are used in human activities, such as manufacturing, mining, agricultural fields, configuring exposure as environmental and occupational risks. Conversely, other metals can be found in water and the food supply chain, posing a safety concern for human health, particularly in developing countries. Arsenic (As), cadmium (Cd), chromium $(\mathrm{Cr})$ and nickel $(\mathrm{Ni})$ are classified as group 1 carcinogens by the International Agency for Research on Cancer (13).

Heavy metals can affect target organs (liver, kidneys, lungs) through different mechanisms and pathways (14). Moreover, these metals are difficult to degrade and their bioaccumulation is dependent not only on the exposure (concentration and frequency), but also on the organism capability to eliminate the metals. The residuals in the gastrointestinal tract can affect the human GM that interacts with heavy metals, and is in part, responsible for the intestinal barrier functioning involved in the control of absorption of toxic metals (15).

All studies on humans or different animal models or in vitro, concerning investigations of $\geq 2$ heavy metals, are concordant in concluding that heavy metal exposure, even if for a short period of time, can cause perturbations in the composition, structure and diversity of the GM. The majority of the studies used the amplification and sequencing of the $16 \mathrm{~S}$ rRNA gene for the microbial community analysis; only 2 studies $(16,17)$, proceeded with metabolomics approach demonstrating that $\mathrm{As}, \mathrm{Cd}$ and selenate also influenced several metabolic pathways. When investigated together, different toxicants may interact and their effects, on GM or on health status, could be potentiated.

Human studies. Laue et al conducted a study on 179 6-week-old infants (18), the GM was assessed using 16S rRNA sequencing. They found that postnatal exposure to toxic elements was differentially associated with the infant microbiota. Exposure was negatively associated with microbial diversity, particularly in infants exposed to peripartum antibiotics. As, Cd, manganese $(\mathrm{Mn})$, copper $(\mathrm{Cu})$, iron $(\mathrm{Fe})$, lead $(\mathrm{Pb}), \mathrm{Ni}$, selenium, tin, and zinc $(\mathrm{Zn})$ were each differentially associated with at least one taxon, in particular with Bacteroides and Lactobacillales, while mercury $(\mathrm{Hg})$ was associated with specific taxa.

In addition, on children aged from 3-7 years, other authors investigated potential interactions between toxic metals, the gut microbiome and the development of autism spectrum disorders (ASDs). The levels of $\mathrm{Pb}, \mathrm{Cd}, \mathrm{As}, \mathrm{Cu}, \mathrm{Zn}, \mathrm{Fe}, \mathrm{Hg}$, calcium and magnesium in hair samples were analyzed. Microbial DNA was extracted from fecal samples and $16 \mathrm{~S}$ rRNA was sequenced. Levels of $\mathrm{Pb}, \mathrm{As}, \mathrm{Cu}, \mathrm{Zn}, \mathrm{Hg}$, calcium and magnesium were significantly higher in the ASD group. Different metals were associated with dissimilar perturbations in GM composition and diversity, suggesting the possible pathogenesis of ASD depending on metal absorption and gut microbial community (19).

Animal studies. Liu et al conducted a study on rats (20), poisoned first with methylmercury $(\mathrm{MeHg})$ and then treated with sodium selenite (NaSe). Microbial DNA was extracted from fecal samples and 16S rRNA was sequenced. The results suggested that $\mathrm{MeHg}$ damaged the composition of microbiota. Following Se treatment, the richness of gut microbial community was partially reestablished and a similar mechanism can be hypothesized also for human beings. A most recent study 


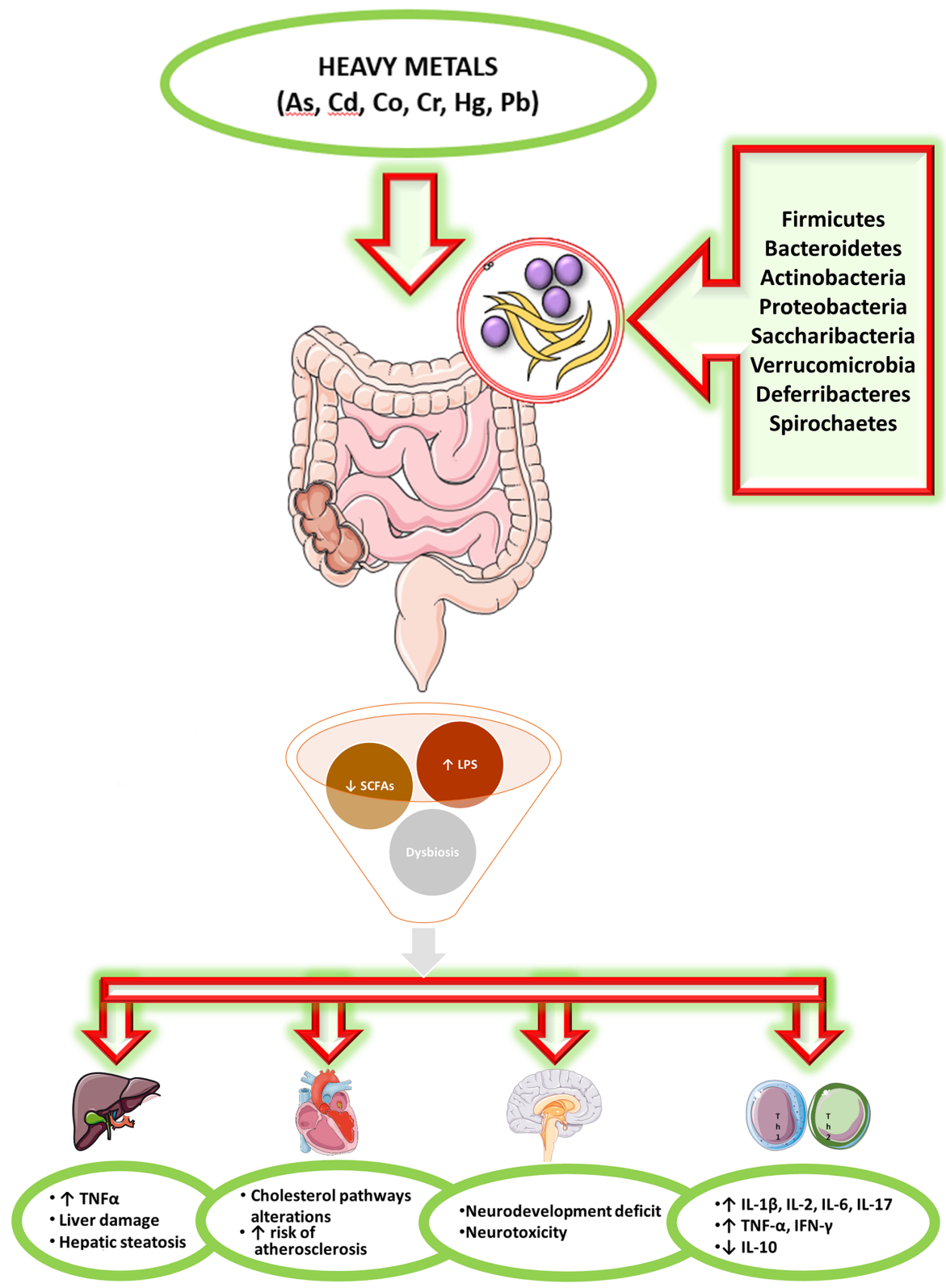

Figure 1. Effects of heavy metals on the microbiota and their impact on health.

performed on rats focused on neuro-developmental effects (21) Offspring rats were exposed to inorganic As (iAs) and fluoride (F-). DNA was extracted from fecal samples and $16 \mathrm{~S}$ rRNA gene was sequenced. Noticeable neuro-developmental effects were observed in rats concurrently exposed to iAs and F-so microbiome-based biomarkers of iAs and/or F-may be suggested as early indicators of neuro-developmental deficits. Richardson et al exposed rats to 3 different doses of sodium arsenite, $\mathrm{Cd}$ chloride, sodium dichromate, cobalt chloride or Ni chloride by oral gavage for 5 consecutive days (14). DNA was extracted from fecal samples and 16S rRNA gene was sequenced. Significant variations in GM composition were observed in high doses of $\mathrm{Cr}$ and cobalt, but only in $\mathrm{As}, \mathrm{Cd}$ and $\mathrm{Ni}$ exposure in a significant dose-dependent manner. Following As and Ni exposure, bacteria with a huge number of iron-importing gene were excessively represented. The results underline the convenience of the microbiome as an early tool for recognizing specific heavy metal exposures (14).
Recently, in a study on mice (22), animals were exposed to $\mathrm{Cu}, \mathrm{Hg}$ or both. DNA was extracted from cecal contents and $16 \mathrm{~S}$ rRNA was sequenced. All treatment groups showed intestinal histopathological damages and alterations in the diversity of gut microbiota in the cecum of female mice, which can provide new insight into the risk assessment in intestinal disorders caused by $\mathrm{Cu}$ and $\mathrm{Hg}$. Gaulke et al fed mice with diet containing either different $\mathrm{Zn}$ concentrations and exposed to As for 6 weeks (23). Zn deficiency and As exposure autonomously changed microbiota composition but, when in combination, the outcomes in microbial community were intensified, in particular marginal $\mathrm{Zn}$ deficiency resulted in a higher sensitiveness to As exposure of the GM (23).

Li et al treated mice with $\mathrm{Cd}$ chloride and As in their drinking water for 2 weeks. Colon and caecum content were collected and 16S rRNA gene was sequenced (16). Both As and $\mathrm{Cd}$ significantly perturbed the metabolome and lowered the GM diversity; however, only Cd significantly decreased 
the microbial diversity. The number of metabolite interactions diminished in a number of genera. Moreover, As and $\mathrm{Cd}$ exposure affected pathways involved in metabolic health (16). Previously, other authors performed a research on cows. Animals were fed supplemental $\mathrm{Cu}, \mathrm{Zn}$, and $\mathrm{Mn}$ from sulfate minerals, glycinate minerals or $\mathrm{Cu}$ and $\mathrm{Mn}$ sulfate with glycinate Zn. Treponema Operational Taxonomic Units (OTU) in GM, frequently related to bovine digital dermatitis, were less abundance in cows fed with $\mathrm{Cu}$ and $\mathrm{Mn}$ sulfate with glycinate $\mathrm{Zn}$. These results suggest a further connection between organic Zn supplementation and better animal health (24). Rothman et al carried out a study on honey bees administering solutions of $50 \%$ sucrose spiked with $\mathrm{Cd}$ chloride, pollen patties spiked with selenium or $\mathrm{Cd}$. Cd and selenate exposure perturbed the composition of the GM altering the metabolite pathways, particularly those concerning detoxification, proteolysis, and lipolysis, resulting in bioaccumulation of these toxicants (17).

In a study conducted on black soldier fly larvae, the authors administered $\mathrm{Cu}$ or $\mathrm{Cd}$. Gut DNA samples were analyzed. $\mathrm{Cu}$ and $\mathrm{Cd}$ exposure noticeably perturbed the GM. The highest levels of exposure significantly reduced the richness of the majority of dominant families; however, in the meantime, other families were enriched, resulting in a total decrease of the GM diversity (25). Zhang et al examined the GM of Bufo raddei from a polluted and relatively unpolluted area (15). The Firmicutes/Bacteroidetes ratio and the number of probiotics in the gut microbiota from the polluted area were decreased when compared to those from the unpolluted are. The results suggest that long-term heavy metal exposure perturbed the structure and reduced the diversity of thee GM in Bufo raddei (15).

In vitro studies. By using the Simulator of the Human Intestinal Microbial Ecosystem (SHIME) some authors have simulated an exposure to As and $\mathrm{Fe}$ in different concentrations suggesting that GM had a significant role in As species modification, and Fe can influence As transformation through alterations in GM. In the evaluation of the health hazards of As in drinking water, the residual Fe should be taken into account (26). Recently, always through the use of the SHIME, fresh fecal microorganisms obtained from volunteers were mixed with Fe minerals (goethite and jarosite). Total and bioaccessible As and Fe concentrations were determined. As bioavailability in human intestine was mainly due to $\mathrm{Fe}^{\mathrm{III}}$ dissolution in jarosite, and to bacterial community reduction of $\mathrm{Fe}^{\mathrm{III}}$ and $\mathrm{As}^{\mathrm{V}}$ in goethite, underlining the importance of Fe minerals in human health risk evaluation associated with environmental As exposure (27).

\section{Arsenic}

As, an ubiquitous nonmetal in nature, is a human carcinogen. While it can be found as a metal in its pure form, it is typically found as a component in both inorganic and organic compartments (28). As is found in water and food worldwide, as both organic and inorganic species in dietary essentials, such as rice, and exclusively as inorganic As in water (29). As soil and water contamination has been associated with human activities, such as smelting, mining, coal and ash disposal, pesticide use (30). As exposure is a public health concern worldwide; in fact, $>100$ million individuals are exposed to As from drinking water and it has been associated to a number of human diseases, particularly diabetes, cancer and cardiovascular illnesses (31). The consumption of contaminated drinking water and/or food is the principal pathway of As exposure in humans; thus, the GM can be the most vulnerable to As exposure (32).

Human studies. Hoen et al analyzed, on 204 infants in the USA, As levels in urine and microbiota composition from fecal samples (29). With higher As exposure, 8 genera were enriched. Urinary As levels were negatively associated with 15 genera, including Bacteroides and Bifidobacterium. Following stratification by sex and feeding method, associations were found in formula-fed males, but not in the other groups. In infant development, sex-specific effects on the GM can be observed even with moderate As exposure (29).

A longitudinal study on the health effects of As conducted in Bangladesh among 250 participants, aimed to find associations between As exposure, microbiota composition and carotid intima-media thickness. Significant associations between GM composition and As exposure were not found. Intima-media thickness (IMT) was significantly associated with Aeromonadaceae and the genus Citrobacter. A significant reciprocity between water As and Citrobacter was observed in IMT. The authors concluded that in the development of atherosclerosis, GM may have an important impact, in particular among subjects exposed to higher As levels (33).

Other authors evaluated 16S rRNA gene sequencing from fecal samples and urine As concentration in 2 southern Nepal communities. Pathogenic bacteria were positively associated with higher As concentrations in the subjects. Lower levels of As were associated with intestinal commensal bacteria. The authors stated that As plays a role in the GM shaping through the enrichment of pathogens and the weakening of commensal bacteria (34).

Previously, a study conducted among children (32) made a comparison between high and low As-exposed groups. Children exposed to higher As concentrations exhibited an abundance of Proteobacteria in their feces. In the high exposed group, a positive association between genes involved in virulence and multidrug resistance and As concentration was observed. The qPCR quantification of 2 As resistant genes (ArsB, ArsC) revealed a higher expression of these 2 operons in the children with high As exposure.

These studies conducted on humans evaluated the gut microbiome composition through the $16 \mathrm{~S}$ rRNA gene sequencing from fecal samples. All the studies, except one (33), found an association between As exposure and significant variations in the gut microbiome, with an increase in the number of pathogens, underlining an important role, played by As exposure.

Animal studies. Coryell et al exposed mice to As. As levels in feces and in organs were measured and the GM composition was analyzed through the 16S rRNA gene sequencing from fecal samples (28). The lack of As detoxification enzyme (As3mt) rendered the mice hypersensitive to As. The protection deriving from humane microbiome transplant depended on microbiota stability and the presence of certain 
bacteria, including Faecalibacterium. In mouse model As3mt and certain microbiota bacteria are fundamental for protection against acute As toxicity (28). Previously, other authors divided mice in cases and controls, treated with sodium arsenite in their drinking water for 13 weeks. In the microbiota of mice treated with As, the genes involved in the biosynthesis of lipopolysaccharides (LPS), in DNA repair mechanisms and in multidrug resistance were increased and the genes involved in the production of vitamins (B6 and B12) were enriched (35). The same authors recently conducted a study on same animals to compare GM-disrupted animals (treated with antibiotics for $72 \mathrm{~h}$ prior to As exposure) and non-antibiotic-treated mice. In the GM-disrupted mice, total As levels were lower in feces and much higher in urine than the levels in control subgroup mice. The disruption of the microbiota significantly altered As biotransformation by affecting one-carbon metabolism and also increased the As toxic effects (36).

Other authors compared Helicobacter-free mice and Helicobacter trogontum-treated animals (by oral gavage) successively treated with As. As exposure caused GM perturbation inducing variations of several metabolite pathways, involving the metabolism of fatty acid, phospholipids, cholesterols, and tryptophan. The authors proposed that GM perturbation could worsen or cause metabolic disturbances induced by As exposure (37). Chi et al treated mice with As for 4 weeks and evaluated variations in microbiota composition (31). At the end of the 4-week treatment, it changed in both males and females, but more significantly in females than in the respective controls. The host sex determines the microbiota phenotypes, whose sensitivity to As differs between male and female mice. Moreover, same authors compared antibiotic and non-antibiotic treated mice. As exposure suppressed gene expression in cholesterol metabolism, transportation and synthesis only in control mice. In antibiotic-treated mice, a smaller perturbation was observed on liver and serum lipid homeostasis caused by As exposure. The As-induced effects on lipid metabolism may be buffered by regulating the GM (38).

In another study, mice were divided into the control and As-treated groups. In As-exposed mice, the $\alpha$-diversity of the GM was significantly lower than that of the controls. Following As exposure, carbohydrate metabolism was significantly perturbed due to the increase of several proteins involved in this pathway. As exposure may increase the LPS synthesis in the GM through the upregulation of UDP-N-acetylglucosamine acyltransferase (39).

Chiocchetti et al administered various doses of $\mathrm{As}^{\mathrm{III}}$ through drinking water to mice (40), evaluating the expression of genes encoding inflammatory cytokines (TNF $\alpha$, IL-1 $\beta$, IL-2 and IL-6) and claudins (Cldn-1, Cldn-2 and Cldn-4). At As concentrations $\geq 50 \mathrm{mg} / \mathrm{l}$, an increase in gene and protein expression of pro-inflammatory cytokines (IL-1 $\beta$, IL-2 and IL-6) was showed. Moreover, the diversity and global composition of GM were accompanied by mucosa and submucosa moderate inflammation. These effects are suggestive of an increased intestinal permeability, resulting in a barrier function loss, particularly at the highest As concentrations.

A study on the adult and developmental stages of CD1 mice (41) evaluated the effects of a single oral exposure and of repeated exposure. In adults after a single gavage, responses in microbial composition and bacterial recovery were observed in a dose and time-dependent manner. Repeated exposure affected intestinal bacteria with a decrease in recovery and an abundance of As resistance genes. High levels of intestine-secreted chemokines were revealed in adult animals exposed to As. Both in juvenile and adult animals, it was possible to observe the gut-associated immune status and intestinal microbiota changes.

Tikka et al compared mice in 2 different exposure periods (3 and 6 months) (42). As exposure not only altered the GM composition, but also increased inflammatory cytokines (TNF- $\alpha$, IFN- $\gamma$ and IL-17) and depleted anti-inflammatory cytokines (IL-10). Moreover, the level of $\beta$-catenin, a colon cancer marker, increased in the animals exposed to As for both 3 and 6 months. These results suggest that variations in the GM can alter inflammatory cytokine pathways, resulting in an immune system dysregulation, affecting colon cancer marker expression (42).

The majority of the studies used C57BL/6 male mice as a study population; other models used were female BALB/c mice, adult and developmental stages of CD1-mice and Kunming mice. All the experiments were designed as control/case studies, exposing animals to various As concentrations in drinking water, in food or oral gavage. The majority of the studies evaluated GM composition through 16S rRNA sequencing from DNA extracted from fecal samples, only two using metagenomic $(31,35)$ and one metaproteomic approaches (39). Data on GM composition, gene expression, metabolic pathways and tissue damage were all concordant on the negative effects elicited by As exposure on animal health status.

A study on the earthworm Metaphire californica (43) evaluated the interactions between microplastics (MPs), As exposure and GM. Following As exposure, significant changes in gut bacterial composition were observed, while MPs did not significantly impact the gut bacterial communities. MPs not only decreased the As accumulation, but also the transformation of $\mathrm{As}^{\mathrm{V}}$ to $\mathrm{As}^{\mathrm{III}}$. MPs may have played a role in lowering As bioavailability, reducing its effects on the GM, resulting in a lower toxicity on earthworms.

Another study on the earthworm (Metaphire sieboldin) compared various As concentrations in the controls and cases for 28 days. The analysis of gene expression revealed that As redox and efflux genes were abundant, whereas As biotransformation (methylation and demethylation) genes were very low. These results suggest that the earthworm GM has a marked capability in reducing $\mathrm{As}^{\mathrm{V}}$ even if As exposure disturbs the GM composition (44).

Studies conducted on worms have demonstrated the negative effects of As exposure on the gut microbiome, resulting in bioaccumulation, reducing capability and gene expression alterations.

In vitro studies. By using the in vitro SHIME, Yin et al aimed to investigate the variability in the As bioaccessibility in gastric, small intestine and colon phases in fecal microorganisms (45). The results suggested that the As bioaccessibility varied in the colon phase, due to microbial reduction activity. In order to assess hazards to human health correlated with oral exposure to soil As, joining in vitro methods and SHIME could increase the accuracy in risk assessment (45). 
The same authors using SHIME, analyzed the interactions between four soils with different As concentrations and fecal microorganisms, demonstrating that human GM can release soil-bound As. In humans subjected to soil As exposure, an precise risk assessment could be carried out by concurrently defining As transformation and intestinal absorption (46).

Li et al demonstrated that the bacterium Bacteroides vulgatus possesses resistance genes to inorganic As, which can be decisive in the ability of the microbe to maintain its prevalence in the human intestine even after exposure to food-related As (47).

In vitro studies, evaluating As bioaccessibility, transformation and absorption, mediated by the human GM, particularly in the colon, play an important role in providing insights on mechanisms involved in As metabolism.

\section{Cadmium}

$\mathrm{Cd}$, one of the most widespread toxic heavy metal pollutants, appears in soils and drinking water supplying, as a side product of human activities, such as mining, agricultural use (in fertilizers) through air deposition or industrial divisions (batteries, pigment and plastics) $(48,49)$. Cd can also be found in aquatic systems. Cd exposure has become a prevalent health concern due to the access to polluted food and water. As with other heavy metals, it is associated to several toxic effects in living organisms, particularly in oxidative stress induction, DNA damage, carcinogenesis, dysregulation in immune responses and energy metabolism (50).

Animal studies. Rodent studies have been designed as control/case experiments, exposing animals to various $\mathrm{Cd}$ concentrations. All studies revealed GM perturbations caused by $\mathrm{Cd}$ exposure and several studies suggested the important role played by $\mathrm{Cd}$ in the alterations of both metabolic and energetic pathways.

Previously, authors demonstrated that the $\mathrm{Cd}$ exposure induced noticeable perturbations of GM in mice, with a significant decrease in gut microbial richness and reduction in short-chain fatty acids (SCFAs) production. Moreover, Cd exposure caused changes in the expression of those genes involved in metabolic pathways, associated with amino acid and carbohydrate (48).

In mice, $\mathrm{Cd}$ exposure significantly altered the GM composition and richness, not only at the phylum level, but also at the family and genus levels. These alterations result in an increase in serum LPS levels accompanied by hepatic inflammation, as a result of dysregulation in energy metabolism (50).

Ba et al evaluated metabolic effects in mice in a sex-dependent perspective, observing that early low-dose Cd exposure (100 nM) altered the GM in composition and diversity. Furthermore, $\mathrm{Cd}$ exposure caused metabolic effects only in males (51).

The only experiment concerning the evaluation of a potential protective probiotic to decrease Cd toxicity, revealed the failure of Akkermansia muciniphila (AKK). GM alterations were observed both in acute and chronic $\mathrm{Cd}$ exposure; however, the oral administration of AKK influenced GM composition, particularly following acute $\mathrm{Cd}$ exposure (52).

Following Cd exposure, a previous study observed both in the liver and GM, noticeable functional and structural modifications. Moreover, $\mathrm{Cd}$ exposure induced variations of several metabolites, suggesting that $\mathrm{Cd}$ may play an important role in energy metabolism in these animals (53).

Studies on fish and crustaceans underlined the negative effects of $\mathrm{Cd}$ on microbial community diversity. In particular, dietary supplementation with probiotics revealed the protective role of certain microorganisms against $\mathrm{Cd}$ bioaccumulation and its toxic effects, providing new insight into aquaculture and food safety. In a study conducted on common carp, it was observed that $\mathrm{Cd}$ exposure significantly perturbed the composition of GM in the fish, resulting in a decrease in microbial community diversity. Conversely, the abundance of $A K K$, decreased after $\mathrm{Cd}$ exposure (54).

Cd exposure caused, in Procambarus clarkii, intestinal histological damage and variations in the richness, diversity and composition of the GM, not only at the phylum level, but also at the genus level. Moreover, Cd exposure may suggestively perturb metabolic pathways related to diseases and cellular processes (55).

Wang et al highlighted the protective effect of Bacillus cereus against $\mathrm{Cd}$ exposure (56). Cd caused manifest variations in the GM composition of Carassius auratus gibelio; however, Bacillus cereus succeeded to inverse these effects, inhibiting perturbations in $\mathrm{Cd}$ bioaccumulation and antioxidant enzyme levels (56). Cd exposure was also shown to cause a marked decay in gut microbial diversity and composition in Nile tilapia. Dietary supplementation with the probiotic Lactobacillus plantarum, CCFM8610, inverted the variations and reduced Cd accumulation (57).

Studies on amphibians have also disclosed $\mathrm{Cd}$ toxic effects, reducing GM diversity and composition. Ya et al observed severe gut histopathological modifications and microbial alterations at the $\mathrm{Cd}$ highest doses (100 and $200 \mu \mathrm{g} / \mathrm{l}$ ), whilst small intestine damage was observed at the $5 \mu \mathrm{g} / \mathrm{l} \mathrm{Cd}$ concentration $(58,59)$. Even in Rana chensinensis, Cd exposure transformed the composition and reduced the microbial diversity in GM both at phylum and genus levels (60).

In addition, 2 studies on worms confirmed the same negative effects of $\mathrm{Cd}$ exposure on GM composition. Notably, variations in intestinal microbial communities in earthworm could be considered as a biological indicator of soil pollution. Šrut et al revealed a perturbation in GM composition and increased levels of heavy metal resistant bacteria following $\mathrm{Cd}$ exposure in the earthworm (49). Lee et al compared the effects of $\mathrm{Cd}$ exposure between Caenorhabditis elegans fed with either soil microbial community (SMB) or Escherichia Coli strain OP50; in the OP50-fed worms, microbial community alterations mediated were particularly severe (61).

\section{Mercury}

Mercury is an ubiquitous and highly biopersistent pollutant. For this reason, environmental and occupational exposure has been subjected to restriction by the European Community. Generally, individuals are exposed via contaminated food consumption, particularly fish. Bioavailable organo-metallic compounds (e.g., MeHg) can cross the blood-brain and placental barriers, developing neurotoxicity $(62,63)$.

The mechanisms involved in the complex bio-physicochemical process of $\mathrm{Hg}$ methylation and demethylation remain 
to be fully understood. However, $\mathrm{MeHg}$ metabolism is the core research in experiments focused on methylation/demethylation processes in GM, that is considered to be involved in the biochemical interplay responsible for its demethylation to inorganic mercury (64).

Human studies. Rothenberg et al analyzed, in pregnant women, total $\mathrm{Hg}$ and $\mathrm{MeHg}$ levels in maternal blood and stool samples, aiming to investigate whether associations between biomarkers for prenatal $\mathrm{MeHg}$ exposure and maternal GM differed between early and late gestation (64). The GM differed, not only between subjects, but also between early and late gestation in the same individual. Even low $\mathrm{MeHg}$ concentrations (both in blood and stool) were associated with perturbations in microbiota composition only during early gestation. The results suggested that mothers ingesting a fiber-rich diet may have significantly improve $\mathrm{MeHg}$ elimination (64).

Animal studies. All in vivo studies were concordant in stating that mercury exposure is accountable for intestinal damage, dysbiosis, metabolic disorders, an increase in the expression of genes involved in apoptosis processes and neurotoxic effects. Some authors also hypothesized that different chemical forms of $\mathrm{Hg}$ are responsible for its accumulation in gut and dissimilar microbiota structure alterations $(62,65,66)$. The GM influences brain activity through the gut-brain axis, by producing neurotransmitters and their precursors. $\mathrm{MeHg}$ can perturbations in GM structure in rodents, resulting in alterations in intestinal neurotransmitters responsible to regulate neuron activity. These results suggest a possible mechanism concerning $\mathrm{MeHg}$ neurotoxicity (63).

\section{Lead}

$\mathrm{Pb}$ has been an ubiquitous environmental pollutant for decades and has been causally associated with well-known occupational diseases and innumerable damaging health effects, including neurological and kidney disorders, anemia and altered immune system responses $(67,68)$. There are a number of sources of lead exposure; apart from water and food, the majority derives from human activities and industrial productions, such as paint and electronic waste (69).

Human studies. Eggers et al found a significant association between the adult urinary $\mathrm{Pb}$ concentration and GM composition, particularly as regards the extent of Proteobacteria colonization (67).

Animal studies. All in vivo studies were concordant in stating that $\mathrm{Pb}$ exposure may play a role in dysbiosis, inducing structural intestinal damage. GM structure and diversity were always perturbed by lead exposure (70). In experimental studies performed on mice, metabolomics profiling and metagenomics sequencing revealed that a number of metabolic pathways, including energy metabolism, oxidative stress and detoxification mechanisms, were meaningfully altered by $\mathrm{Pb}$ exposure (69). $\mathrm{Pb}$ exposure caused memory impairment, perturbations in GM composition and release of oxidative stress biomarkers in serum (71). Prenatal $\mathrm{Pb}$ exposure may also contribute to increase adult bodyweight (72) and can cause large intestine immune disorders (73). The same effects were confirmed in zebrafish (74).

In vitro studies. By SHIME simulation, $\mathrm{Pb}$ bioaccessibility was evaluated in soil samples through the Physiologically Based Extraction Test (PBET). The mean $\mathrm{Pb}$ bioaccessibility changed in gastric, small intestine and colon phases, depending on soil $\mathrm{pH}$ and types. The action of the human GM was important in the colon phase, when mean $\mathrm{Pb}$ bioaccessibility was compared between farming soils (higher) and mining soils (lower) (75).

\section{Zinc}

$\mathrm{Zn}$ is a fundamental nutrient for almost all organisms. From a clinical point of view, even mild deficiencies can reduce cellular differentiation, influence immune system developing and deeply affect growth and maturation (76). Infants, also when healthy, are given additional $\mathrm{Zn}$ with food, beverages and nutritional supplements; consequently, it often exceeds established nutritional necessities (77). Furthermore, the microbial community has its own requirements for minerals, including Zn (78).

Animal studies. The excessive intake of dietary $\mathrm{Zn}$ in mice, can cause oxidative stress in the intestine, resulting in deep shifts in GM. These perturbations are associated with a microbial community enriched in pathogenic taxa. Moreover, variations in the expression of genes involved in metabolic processes, oxidative stress and protein glycosylation were observed (77). Excess dietary Zn not only significantly perturbs the GM, but also worsens $C$. difficile-associated disease, by varying the host immune response (79). In a study conducted on chicken hatchlings (Gallus gallus), animals receiving a Zn-biofortified diet exhibited a significant increase in $\beta$-but not $\alpha$-microbial diversity; in particular, associated intensification in $\mathrm{Zn}$-dependent bacterial metabolic pathways was detected (76). A research conducted on Targhee yearling rams revealed that a quantity of bacterial genera was perturbed, but only the phylum Tenericutes was significantly decreased by $\mathrm{Zn}$ supplementation, suggesting that $\mathrm{Zn}$ formulations can be employed without producing a high-level modification in the rumen gut microbiome composition, which could have adverse effects on metabolism and health status (78). These studies demonstrated how an excess in dietary $\mathrm{Zn}$, not only significantly perturbs microbiota, but also affects different metabolic pathways and gene expression, resulting in negative effects on animal health status.

\section{Copper}

$\mathrm{Cu}$ is an essential microelement (80); however, excessive $\mathrm{Cu}$ quantities can affect the ecosystem resulting in soil and water pollution. Disproportionate $\mathrm{Cu}$ exposure may cause negative effects on animal organisms, inducing respiratory, nervous and gastrointestinal diseases (81). The effects of overexposure to $\mathrm{Cu}$ on the GM are not yet well described in the literature (82).

Animal studies. High $\mathrm{Cu}$ concentrations can cause liver damage in rats. $\mathrm{Cu}$ exposure can exert dose-dependent 
effects on the structure of the GM. Moreover, metabolomic analysis confirmed the effects of $\mathrm{Cu}$ exposure on metabolic pathways involved in hepatic injury and intestinal inflammation. These alterations may induce an inflammatory response, in which TNF- $\alpha$ could be the main respondent in $\mathrm{Cu}$ overexposure $(82,83)$. Furthermore, various dietary doses of $\mathrm{Cu}$ and fructose can interact with host microbial metabolic activities by various mechanisms, resulting in alterations in GM composition, liver damage and hepatic steatosis (84).

In mice, some authors have demonstrated that high concentrations of $\mathrm{Cu}$ can cause intestinal histopathological lesions and perturb GM composition (81). In piglets, a low-Cu diet can alter the structure of the microbiota and modify bacterial metabolic pathways, including proteins, carbohydrates, the urea cycle, gluconeogenesis and amino acids, which may play a role in affecting animal health (80). In a previous study, the $\mathrm{GM}$ of $\mathrm{Cu}$-treated fish (Takifugu fasciatus) exhibited perturbations in composition at the phylum level, revealing the role of intestinal microbial community in maintaining the health status of Takifugu fasciatus for aquaculture (85). In addition, in the common carp (Cyprinus carpio L.), $\mathrm{Cu}$ exposure altered the $\alpha$ - and $\beta$-diversity of the GM (86). The authors observed that the presence of short-chain fatty acid (SCFA)-producing bacteria was significantly reduced, as well as probiotics, with an increase in pathogens, resulting in an increasing risk of pathogen invasion (86). Moreover, in Rana chensinensis larvae, the $\mathrm{Cu}$-altered microbiota composition was observed at the phylum level, resulting in a reduction of Fusobacteria abundance, while Bacteroidetes did not exhibit significant differences (87).

These studies suggest that $\mathrm{Cu}$ exposure exerts dosedependent effects on the structure of the GM. Changes in the composition of the microbial community may be related to alterations in several metabolic pathways, inflammatory responses (through cytokine modulation) and liver damage (88).

\section{Nanoparticles}

Advances in nanotechnology introduced over the last decade have allowed for the production of metals on a nanoscale $(1 \pm 100 \mathrm{~nm})$. Due to their particular characteristics, the applications of nanoparticles (NPs) have been extended in different fields, such as cosmetology, agriculture, textile manufacture, construction, food and medical area, particularly in diagnostic imaging, drug technology and tumor therapies. This widespread introduction of NPs in a number of human activities has unavoidably lead to NP diffusion in the environment (89-92).

Nanoparticles, including metals, due to their small dimensions, are able to cross biological membranes, perturb ion channels transportation, alter enzymatic activities and react with genomic material. These mechanisms could induce tissue injuries, oxidative stress (92) and can modulate immune responses (93).

The majority of studies demonstrate that metal NPs, through different biochemical mechanisms, can perturb the microbiota with negative consequences, particularly when high concentrations in dietary regimens are administered to experimental animals. Nonetheless, there is also evidence of a possible benefit in dietary supplementation with NP.
Animal studies. Cholewińska et al in 2018, revealed that $\mathrm{Cu}$ NPs were better absorbed in the intestines of Wistar rats, but bioaccumulated in the brain, and at a higher dosage induced severe liver injury. As regards GM, Cu NPs blocked its enzymatic activity and consequently significantly reduced SCFA production (92).

$\mathrm{Cu}$ oxide $(\mathrm{CuO}) \mathrm{NP}$ exposure can not only induce perturbations in microbiota composition, but can also affect the expression of genes involved in immune response in worms, such as lysozyme and coelomic cytolytic factor. Nonetheless, these alterations in the microbiome did not increase susceptibility to bacterial infection (93). In another study, in poultry, $\mathrm{CuO} \mathrm{NP}$ added to the feed, did not affect probiotics or the main representatives of normal microbial community. The $\mathrm{Cu}$ active ions, due to the low dissociation degree from NP, are released more slowly and therefore have more prolonged positive effects (94).

In a study conducted on Eisenia fetida cultured with zinc NP in soil, 35\% mortality and perturbations in GM composition were observed, and in particular, a decrease in microbial diversity was registered (89). Wang et al exposed mice to nano- $\mathrm{ZnO}$ suspension, which raised $\mathrm{Zn}$ concentrations in the serum, liver and kidneys, but did not perturb the gut microbiome composition (95). Some authors have hypothesized an increment of anti-inflammatory activity in $\mathrm{ZnO}$ NP-exposed mice. The effects of $\mathrm{ZnO}$ NP varied in the GM, increasing Firmicutes and decreasing Bacteroidetes in female mice. SCFA were also increased, indicating that $\mathrm{ZnO}$ NP could have possible utilizations as safe regulators of GM (96). In crossbred weaned piglets, fed a diet supplemented with nano-Zn, positive effects on gut morphology and microbiota were observed, similar to those of conventional $\mathrm{ZnO}$ (97). Kolba et al demonstrated that different metal NPs $\left(\mathrm{TiO}_{2}, \mathrm{SiO}_{2}\right.$ and $\left.\mathrm{ZnO}\right)$ could perturb the composition of the GM, negatively influencing intestinal functions and health in chicken (Gallus gallus) (98).

In vitro studies. The antimicrobial and antioxidant effects of green silver nanoparticles (Ag NP) on the GM in healthy individuals have been simulated by an in vitro one-chamber GIS1 colon simulator. Ag NP preserved their antioxidant properties, as shown by a decrease in ammonium compounds; a decrease in Bacteroides suggested an antimicrobial effect. Moreover, the NP spherical shape was significantly associated with their biological outcomes in vitro (99).

\section{Other heavy metals}

$\mathrm{Cr}$ is an essential trace element with positive health outcomes, which are well demonstrated in humans and animals. Feeding mice with supplementary Cr-enriched B. subtilis combined the benefits of $\mathrm{Cr}$ and probiotics and positively influenced caecal microbiota, tissue $\mathrm{Cr}$ concentrations, insulin receptor expression and plasma biochemical profile (100).

However, $\mathrm{Cr}$ is also one of the major inorganic heavy metals and its detrimental action in the environment is well known. $\mathrm{Cr}$ in aquatic environments, deriving from human activities (textiles, electroplating and printing), is biologically toxic, particularly in the hexavalent form $\mathrm{Cr}^{\mathrm{VI}}$. There is limited evidence on the negative effects of $\mathrm{Cr}$ exposure on the GM; according to Yao et al, $\mathrm{Cr}^{\mathrm{VI}}$ can significantly perturb GM 


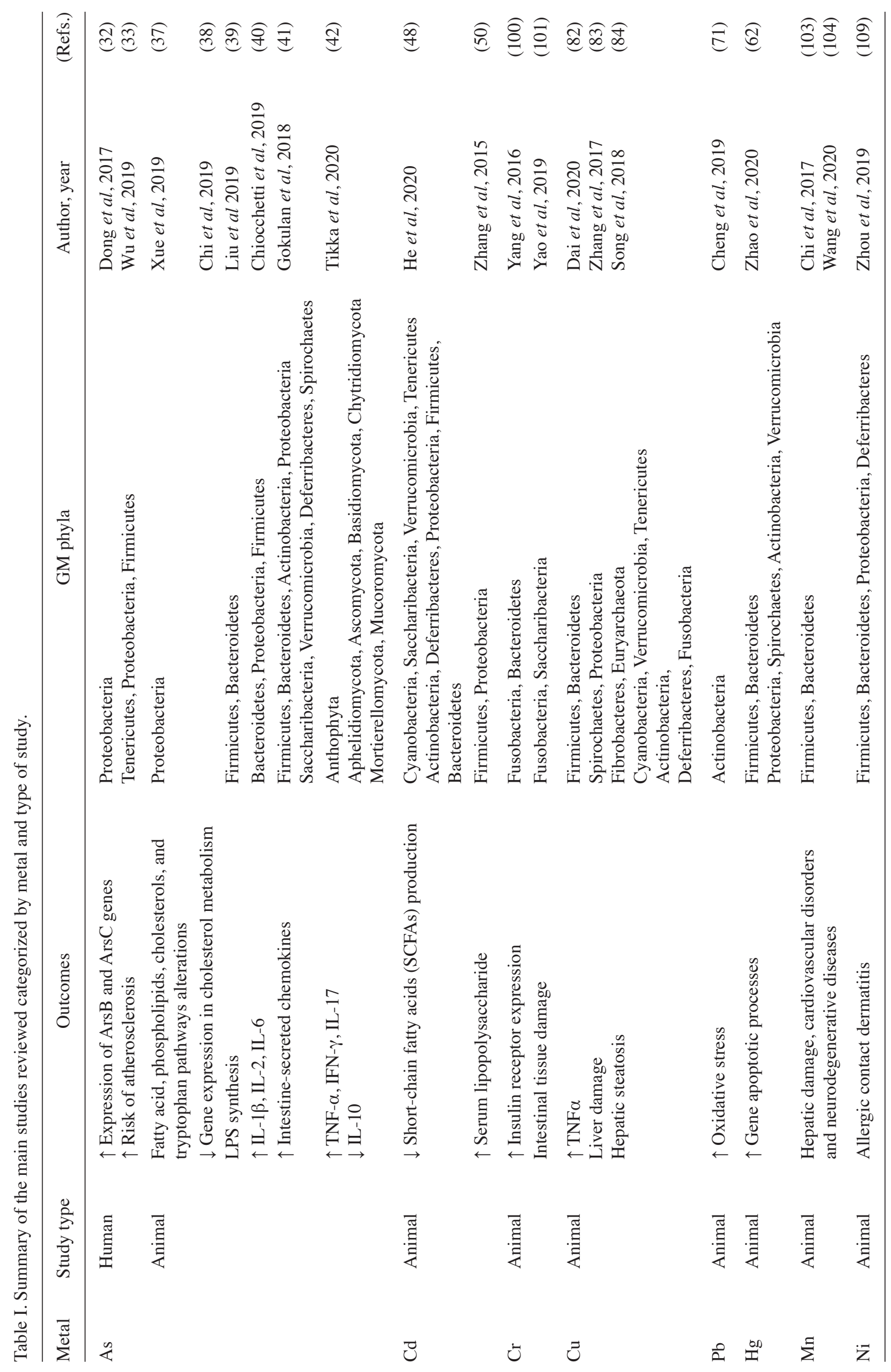


composition and can cause intestinal tissue damage when administrated in Bufo gargarizans (101). In mice, it perturbed microbiota composition and structure. Still, researchers have observed that Lactobacillus plantarum TW1-1 partially inversed $\mathrm{Cr}$ exposure-linked effects (102).

$\mathrm{Mn}$, an essential element, is fundamental for physiological brain functioning and main metabolic pathways, including enzymes. In spite of this, an excessive Mn intake is related to hepatic damage, cardiovascular disorders and neurodegenerative diseases (103), as a result of chronic or acute exposure, also deriving from professional sources (104). The majority of $\mathrm{Mn}$ intake is derived from water and food; however, the interactions between GM and this element are not straightforward. Chi et al demonstrated that Mn exposure can alter the GM structure in a sex-specific manner in mice, can change metabolic profiles and the expression of bacterial genes involved in neurotransmitter biosynthesis and inflammatory cytokines (103). Moreover, Mn exposure can induce hippocampal deterioration and death in rats, also perturbing GM composition and changing the metabolism of tryptamine. Fecal microbiota transplantation (FMT) could lessen the neurological toxic effect of Mn through influencing the gut microbiome (104).

In addition, molybdenum (Mo) is an essential element and a crucial constituent of enzymes in living organisms. Mo pollution derives from human activities, such as in mining and incinerators, especially when regulatory standards are not respected. Zhou et al orally administered ammonium molybdate to Boer goats (105). The contents of $\mathrm{Mo}, \mathrm{Cu}, \mathrm{Zn}$ and $\mathrm{Fe}$ in the serum, liver, kidneys, lungs, cardiac muscle, hair and muscle were then analyzed. The data displayed a decrease in ciliate and protozoa protein levels. Mo bioaccumulated in serum and tissues. The excessive Mo intake perturbed the GM balance and interfered with $\mathrm{Cu}$ absorption (105).

Vanadium, a transitional metal and essential element, is a natural constituent of approximately 65 minerals. Although this metal has not shown negative outcomes for human health, several vanadium mixtures can irritate the mucosae and can cause damage to the lungs (106). Recently, toxic effects resulting in GM perturbation have raised a growing interest on this metal in the breeding field, especially poultry (107).

$\mathrm{Ni}$ is a metal commonly found in the environment. It is a well-known causative agent for allergic contact dermatitis deriving from belts, coins, jewelry. Skin contact, inhalation and ingestion from food and stainless steel pots are the main paths through which $\mathrm{Ni}$ exposure can occur (108). In a previous study, when absorbed via oral ingestion in mice, $\mathrm{Ni}$ did not exert toxic effects, but acted on the GM, resulting in alterations in metabolic balance and microbial composition (109).

\section{Conclusion}

The majority of the reviewed studies demonstrated that exposure to metals can alter the composition, diversity, homogeneity and structure of the GM. However, it was clearly indicated that the specific modifications reported are not homogeneous (Table I). A number of factors may explain this variability, including differences in metal compound, exposure modalities (e.g. food, water, in vitro), the duration of exposure, qualitative and quantitative diversity of bacterial species in basal microbiota, analytical issues. As regards the dose, it must be specified that the sensitivity or resistance of the whole GM or of an individual microbe to a given toxicant is strongly dependent on its role in the exposed organism; i.e., essential metals become toxic at very high doses, whereas metals which do not play a biological role cause adverse effects even in very small concentrations. Moreover, the majority of animal studies reported in the present review addressed a single metal, while real-life exposure commonly implies introduction of multiple metals.

Investigations into the effects of nanoparticles did not lead to straightforward conclusions: Some foresee the premises for a safe preventive and therapeutic use, while others have shown harmful effects on both gut microbiome and health. The majority of the reported studies used 16S rRNA sequencing to explore gut microbiome composition and diversity. Only a few studies utilized modern approaches, such as metagenomic sequencing and metabolomics, including the investigation of potential interactions between heavy metals, gut microbiome and metabolic pathways.

Even though further investigations are required, these findings seem to indicate structural and functional analysis of GM as an early biomarker of detrimental effects from exposure to metals.

\section{Acknowledgements}

Not applicable.

Funding

No funding was received.

\section{Availability of data and materials}

Not applicable.

\section{Authors' contributions}

CF and CC conceived the study. RC, NF and GB designed and prepared the review. MT, SI and FG contributed to the study design, and to the writing and editing of the manuscript. All authors reviewed and approved the final manuscript.

\section{Ethics approval and consent to participate}

Not applicable.

\section{Patient consent for publication}

Not applicable.

\section{Competing interests}

The authors declare that they have no competing interests.

\section{References}

1. Hill DA and Artis D: Intestinal bacteria and the regulation of immune cell homeostasis. Annu Rev Immunol 28: 623-667, 2010.

2. Cho I and Blaser MJ: The human microbiome: At the interface of health and disease. Nat Rev Genet 13: 260-270, 2012. 
3. Breton J, Massart S, Vandamme P, De Brandt E, Pot B and Foligné B: Ecotoxicology inside the gut: Impact of heavy metals on the mouse microbiome. BMC Pharmacol Toxicol 14: 62, 2013.

4. World Health Organization (WHO): Trace elements in human nutrition and health. WHO, Geneva, 1996.

5. Rapisarda V, Miozzi E, Loreto C, Matera S, Fenga C, Avola R and Ledda C: Cadmium exposure and prostate cancer: Insights, mechanisms and perspectives. Front Biosci (Landmark Ed) 23: $1687-1700,2018$

6. Fenga C, Gangemi S, Di Salvatore V, Falzone L and Libra M: Immunological effects of occupational exposure to lead. Mol Med Rep 15: 3355-3360, 2017.

7. Planchart A, Green A, Hoyo C and Mattingly CJ: Heavy metal exposure and metabolic syndrome: Evidence from human and model system studies. Curr Environ Health Rep 5: 110-124, 2018

8. Rehman K, Fatima F, Waheed I and Akash MSH: Prevalence of exposure of heavy metals and their impact on health consequences. J Cell Biochem 119: 157-184, 2018.

9. Sommer F and Bäckhed F: The gut microbiota-masters of host development and physiology. Nat Rev Microbiol 11: 227-238, 2013

10. Forbes JD, Van Domselaar G and Bernstein CN: The gut microbiota in immune-mediated inflammatory diseases. Front Microbiol 7: 1081, 2016.

11. Mandel LJ, Bacallao R and Zampighi G: Uncoupling of the molecular 'fence' and paracellular 'gate' functions in epithelial tight junctions. Nature 361: 552-555, 1993.

12. Arumugam M, Raes J, Pelletier E, Le Paslier D, Yamada T, Mende DR, Fernandes GR, Tap J, Bruls T, Batto JM, et al Enterotypes of the human gut microbiome. Nature 473: 174-180, 2011.

13. IARC Monographs: Arsenic, Metals, Fibres, and Dusts. IARC monographs on the evaluation of carcinogenic risk to human. Vol 100C. IARC, Lyon, 2012.

14. Richardson JB Jr, Dancy BCR, Horton CL, Lee YS, Madejczyk MS, Xu ZZ, Ackermann G, Humphrey G, Palacios G, Knight R and Lewis JA: Exposure to toxic metals triggers unique responses from the rat gut microbiota. Sci Rep 8: 6578, 2018.

15. Zhang W, Guo R, Yang Y, Ding J and Zhang Y: Long-term effect of heavy-metal pollution on diversity of gastrointestinal microbial community of Bufo raddei. Toxicol Lett 258: 192-197, 2016.

16. Li X, Brejnrod AD, Ernst M, Rykær M, Herschend J, Olsen NMC Dorrestein PC, Rensing C and Sørensen SJ: Heavy metal exposure causes changes in the metabolic health-associated gut microbiome and metabolites. Environ Int 126: 454-467, 2019.

17. Rothman JA, Leger L, Kirkwood JS and McFrederick QS: Cadmium and selenate exposure affects the honey bee microbiome and metabolome, and bee-associated bacteria show potential for bioaccumulation. Appl Environ Microbiol 85: e01411-19, 2019.

18. Laue HE, Moroishi Y, Jackson BP, Palys TJ, Madan JC and Karagas MR: Nutrient-toxic element mixtures and the early postnatal gut microbiome and in a United States longitudinal birth cohort. Environ Int 138: 105613, 2020.

19. Zhai Q, Cen S, Jiang J, Zhao J, Zhang H and Chen W: Disturbance of trace element and gut microbiota profiles as indicators of autism spectrum disorder: A pilot study of Chinese children. Environ Res 171: 501-509, 2019.

20. Liu Y, Ji J, Zhang W, Suo Y, Zhao J, Lin X, Cui L, Li B, Hu H, Chen $\mathrm{C}$ and $\mathrm{Li}$ YF: Selenium modulated gut flora and promoted decomposition of methylmercury in methylmercury-poisoned rats. Ecotoxicol Environ Saf 185: 109720, 2019.

21. Qiu Y, Chen X, Yan X, Wang J, Yu G, Ma W, Xiao B, Quinones S, Tian X and Ren X: Gut microbiota perturbations and neurodevelopmental impacts in offspring rats concurrently exposure to inorganic arsenic and fluoride. Environ Int 140: 105763, 2020.

22. Ruan Y, Wu C, Guo X, Xu Z, Xing C, Cao H, Zhang C, Hu G and Liu P: High doses of copper and mercury changed cecal microbiota in female mice. Biol Trace Elem Res 189: 134-144, 2019.

23. Gaulke CA, Rolshoven J, Wong CP, Hudson LG, Ho E and Sharpton TJ: Marginal zinc deficiency and environmentally relevant concentrations of arsenic elicit combined effects on the gut microbiome. mSphere 3: e00521-18, 2018.

24. Faulkner MJ, Wenner BA, Solden LM and Weiss WP: Source of supplemental dietary copper, zinc, and manganese affects fecal microbial relative abundance in lactating dairy Cows. J Dairy Sci 100: 1037-1044, 2017

25. Wu N, Wang X, Xu X, Cai R and Xie S: Effects of heavy metals on the bioaccumulation, excretion and gut microbiome of black soldier fly larvae (Hermetia illucens). Ecotoxicol Environ Saf 192: 110323, 2020.
26. Yu H, Wu B, Zhang XX, Liu S, Yu J, Cheng S, Ren HQ and Ye L: Arsenic metabolism and toxicity influenced by ferric iron in simulated gastrointestinal tract and the roles of gut microbiota. Environ Sci Technol 50: 7189-7197, 2016

27. Yin N, Cai X, Zheng L, Du H, Wang P, Sun G and Cui Y: In vitro assessment of arsenic release and transformation from As(V)-sorbed goethite and jarosite: The influence of human gut microbiota. Environ Sci Technol 54: 4432-4442, 2020.

28. Coryell M, McAlpine M, Pinkham N, McDermott TR and Walk ST: The gut microbiome is required for full protection against acute arsenic toxicity in mouse models. Nat Commun 9: 5424,2018

29. Hoen AG, Madan JC, Li Z, Coker M, Lundgren SN, Morrison HG, Palys T, Jackson BP, Sogin ML, Cottingham KL and Karagas MR: Sex-specific associations of infants' gut microbiome with arsenic exposure in a US population. Sci Rep 8: 12627, 2018.

30. Baker BA, Cassano VA, Murray C and Dreger M: Arsenic exposure, assessment, toxicity, diagnosis, and management: Guidance for occupational and environmental physicians. J Occup Environ Med 60: e634-e639, 2018.

31. Chi L, Bian X, Gao B, Ru H, Tu P and Lu K: Sex-specific effects of arsenic exposure on the trajectory and function of the gut microbiome. Chem Res Toxicol 29: 949-951, 2016.

32. Dong X, Shulzhenko N, Lemaitre J, Greer RL, Peremyslova K, Quamruzzaman Q, Rahman $\mathrm{M}$, Hasan OS, Joya SA, Golam M, et al: Arsenic exposure and intestinal microbiota in children from Sirajdikhan, Bangladesh. PLoS One 12: e0188487, 2017.

33. Wu F, Yang L, Islam MT, Jasmine F, Kibriya MG, Nahar J, Barmon B, Parvez F, Sarwar G, Ahmed A, et al: The role of gut microbiome and its interaction with arsenic exposure in carotid intima-media thickness in a Bangladesh population. Environ Int 123: 104-113, 2019.

34. Brabec JL, Wright J, Ly T, Wong HT, McClimans CJ, Tokarev V, Lamendella R, Sherchand S, Shrestha D, Uprety S, et al: Arsenic disturbs the gut microbiome of individuals in a disadvantaged community in Nepal. Heliyon 6: e03313, 2020.

35. Chi L, Bian X, Gao B, Tu P, Ru H and Lu K: The effects of an environmentally relevant level of arsenic on the gut microbiome and its functional metagenome. Toxicol Sci 160: 193-204, 2017.

36. Chi L, Xue J, Tu P, Lai Y, Ru H and Lu K: Gut microbiome disruption altered the biotransformation and liver toxicity of arsenic in mice. Arch Toxicol 93: 25-35, 2019.

37. Xue J, Lai Y, Chi L, Tu P, Leng J, Liu CW, Ru H and Lu K: Serum metabolomics reveals that gut microbiome perturbation mediates metabolic disruption induced by arsenic exposure in mice. J Proteome Res 18: 1006-1018, 2019.

38. Chi L, Lai Y, Tu P, Liu CW, Xue J, Ru H and Lu K: Lipid and cholesterol homeostasis after arsenic exposure and antibiotic treatment in mice: Potential role of the microbiota. Environ Health Perspect 127: 97002, 2019.

39. Liu CW, Chi L, Tu P, Xue J, Ru H and Lu K: Isobaric Labeling quantitative metaproteomics for the study of gut microbiome response to arsenic. J Proteome Res 18: 970-981, 2019.

40. Chiocchetti GM, Domene A, Kühl AA, Zúñiga M, Vélez D, Devesa V and Monedero V: In vivo evaluation of the effect of arsenite on the intestinal epithelium and associated microbiota in mice. Arch Toxicol 93: 2127-2139, 2019.

41. Gokulan K, Arnold MG, Jensen J, Vanlandingham M, Twaddle NC, Doerge DR, Cerniglia CE and Khare S: Exposure to arsenite in CD-1 mice during juvenile and adult stages: Effects on intestinal microbiota and Gut-associated immune status. mBio 9: e01418-18, 2018.

42. Tikka C, Manthari RK, Ommati MM, Niu R, Sun Z, Zhang J and Wang J: Immune disruption occurs through altered gut microbiome and NOD2 in arsenic induced mice: Correlation with colon cancer markers. Chemosphere 246: 125791, 2020.

43. Wang HT, Ding J, Xiong C, Zhu D, Li G, Jia XY, Zhu YG and Xue XM: Exposure to microplastics lowers arsenic accumulation and alters gut bacterial communities of earthworm Metaphire californica. Environ Pollut 251: 110-116, 2019.

44. Wang HT, Zhu D, Li G, Zheng F, Ding J, O'Connor PJ, Zhu YG and Xue XM: Effects of arsenic on gut microbiota and its biotransformation genes in earthworm metaphire sieboldi. Environ Sci Technol 53: 3841-3849, 2019.

45. Yin N, Du H, Zhang Z, Cai X, Li Z, Sun G and Cui Y: Variability of arsenic bioaccessibility and metabolism in soils by human gut microbiota using different in vitro methods combined with SHIME. Sci Total Environ 566-567: 1670-1677, 2016. 
46. Yin N, Cai X, Du H, Zhang Z, Li Z, Chen X, Sun G and Cui Y: In vitro study of soil arsenic release by human gut microbiota and its intestinal absorption by Caco- 2 cells. Chemosphere 168 : 358-364, 2017

47. Li J, Mandal G and Rosen BP: Expression of arsenic resistance genes in the obligate anaerobe Bacteroides vulgatus ATCC 8482, a gut microbiome bacterium. Anaerobe 39: 117-123, 2016.

48. He X, Qi Z, Hou H, Qian L, Gao J and Zhang XX: Structural and functional alterations of gut microbiome in mice induced by chronic cadmium exposure. Chemosphere 246: 125747, 2020.

49. Srut M, Menke S, Höckner M and Sommer S: Earthworms and cadmium-Heavy metal resistant gut bacteria as indicators for heavy metal pollution in soils? Ecotoxicol Environ Saf 171: 843-853, 2019.

50. Zhang S, Jin Y, Zeng Z, Liu Z and Fu Z: Subchronic exposure of mice to cadmium perturbs their hepatic energy metabolism and gut microbiome. Chem Res Toxicol 28: 2000-2009, 2015.

51. Ba Q, Li M, Chen P, Huang C, Duan X, Lu L, Li J, Chu R, Xie D, Song H, et al: Sex-dependent effects of cadmium exposure in early life on gut microbiota and fat accumulation in mice. Environ Health Perspect 125: 437-446, 2017

52. Feng S, Liu Y, Huang Y, Zhao J, Zhang H, Zhai Q and Chen W: Influence of oral administration of Akkermansia muciniphila on the tissue distribution and gut microbiota composition of acute and chronic cadmium exposure mice. FEMS Microbiol Lett 366: fnz160, 2019

53. He X, Qi Z, Hou H, Gao J and Zhang XX: Effects of chronic cadmium exposure at food limitation-relevant levels on energy metabolism in mice. J Hazard Mater 388: 121791, 2020.

54. Chang X, Li H, Feng J, Chen Y, Nie G and Zhang J: Effects of cadmium exposure on the composition and diversity of the intestinal microbial community of common carp (Cyprinus carpio L.). Ecotoxicol Environ Saf 171: 92-98, 2019.

55. Zhang Y, Li Z, Kholodkevich S, Sharov A, Chen C, Feng Y, Ren $N$ and Sun K: Effects of cadmium on intestinal histology and microbiota in freshwater crayfish (Procambarus clarkii). Chemosphere 242: 125105, 2020.

56. Wang N, Jiang M, Zhang P, Shu H, Li Y, Guo Z and Li Y: Amelioration of $\mathrm{Cd}$-induced bioaccumulation, oxidative stress and intestinal microbiota by Bacillus cereus in Carassius auratus gibelio. Chemosphere 245: 125613, 2020.

57. Zhai Q, Yu L, Li T, Zhu J, Zhang C, Zhao J, Zhang H and Chen W: Effect of dietary probiotic supplementation on intestinal microbiota and physiological conditions of Nile tilapia (Oreochromis niloticus) under waterborne cadmium exposure. Antonie Van Leeuwenhoek 110: 501-513, 2017.

58. Ya J, Ju Z, Wang $\mathrm{H}$ and Zhao $\mathrm{H}$ : Exposure to cadmium induced gut histopathological damages and microbiota alterations of Chinese toad (Bufo gargarizans) larvae. Ecotoxicol Environ Saf 180: 449-456, 2019

59. Ya J, Li X, Wang L, Kou H, Wang H and Zhao H: The effects of chronic cadmium exposure on the gut of Bufo gargarizans larvae at metamorphic climax: Histopathological impairments, microbiota changes and intestinal remodeling disruption. Ecotoxicol Environ Saf 195: 110523, 2020.

60. Mu D, Meng J, Bo X, Wu M, Xiao H and Wang H: The effect of cadmium exposure on diversity of intestinal microbial community of Rana chensinensis tadpoles. Ecotoxicol Environ Saf 154: 6-12, 2018.

61. Lee S, Kim Y and Choi J: Effect of soil microbial feeding on gut microbiome and cadmium toxicity in Caenorhabditis elegans. Ecotoxicol Environ Saf 187: 109777, 2020.

62. Zhao Y, Zhou C, Wu C, Guo X, Hu G, Wu Q, Xu Z, Li G, Cao H, Li L, et al: Subchronic oral mercury caused intestinal injury and changed gut microbiota in mice. Sci Total Environ 721: 137639, 2020

63. Lin X, Zhao J, Zhang W, He L, Wang L, Chang D, Cui L, Gao Y, Li B, Chen C and Li YF: Acute oral methylmercury exposure perturbs the gut microbiome and alters gut-brain axis related metabolites in rats. Ecotoxicol Environ Saf 190: 110130, 2020.

64. Rothenberg SE, Wagner CL, Hamidi B, Alekseyenko AV and Andrea Azcarate-Peril M: Longitudinal changes during pregnancy in gut microbiota and methylmercury biomarkers, and reversal of microbe-exposure correlations. Environ Res 172: 700-712, 2019

65. Zhang BB, Liu YM, Hu AL, Xu SF, Fan LD, Cheng ML, Li C, Wei LX and Liu J: $\mathrm{HgS}$ and Zuotai differ from $\mathrm{HgCl} 2$ and methyl mercury in intestinal $\mathrm{Hg}$ absorption, transporter expression and gut microbiome in mice. Toxicol Appl Pharmacol 379: 114615, 2019.

66. Zhou C, Xu P, Huang C, Liu G, Chen S, Hu G, Li G, Liu P and Guo X: Effects of subchronic exposure of mercuric chloride on intestinal histology and microbiota in the cecum of chicken. Ecotoxicol Environ Saf 188: 109920, 2020
67. Eggers S, Safdar N, Sethi AK, Suen G, Peppard PE, Kates AE, Skarlupka JH, Kanarek M and Malecki KMC: Urinary lead concentration and composition of the adult gut microbiota in a cross-sectional population-based sample. Environ Int 133 $105122,2019$.

68. Fenga C, Gangemi S, Alibrandi A, Costa C and Micali E: Relationship between lead exposure and mild cognitive impairment. J Prev Med Hyg 57: E205-E210, 2016.

69. Gao B, Chi L, Mahbub R, Bian X, Tu P, Ru H and Lu K: Multi-omics reveals that lead exposure disturbs gut microbiome development, key metabolites, and metabolic pathways. Chem Res Toxicol 30: 996-1005, 2017.

70. Yu L, Yu Y, Yin R, Duan H, Qu D, Tian F, Narbad A, Chen W and Zhai Q: Dose-dependent effects of lead induced gut injuries: An in vitro and in vivo study. Chemosphere 266: 129130, 2021.

71. Cheng D, Li H, Zhou J and Wang S: Chlorogenic acid relieves lead-induced cognitive impairments and hepato-renal damage: Via regulating the dysbiosis of the gut microbiota in mice. Food Funct 10: 681-690, 2019

72. Wu J, Wen XW, Faulk C, Boehnke K, Zhang H, Dolinoy DC and Xi C: Perinatal lead exposure alters gut microbiota composition and results in sex-specific bodyweight increases in adult mice. Toxicol Sci 151: 324-333, 2016

73. Kou H, Fu Y, He Y, Jiang J, Gao X and Zhao H: Chronic lead exposure induces histopathological damage, microbiota dysbiosis and immune disorder in the cecum of female Japanese quails (Coturnix japonica). Ecotoxicol Environ Saf 183: 109588, 2019.

74. Xia J, Lu L, Jin C, Wang S, Zhou J, Ni Y, Fu Z and Jin Y: Effects of short term lead exposure on gut microbiota and hepatic metabolism in adult zebrafish. Comp Biochem Physiol C Toxicol Pharmacol 209: 1-8, 2018.

75. Du H, Yin N, Cai X, Wang P, Li Y, Fu Y, Sultana MS, Sun G and Cui Y: Lead bioaccessibility in farming and mining soils: The influence of soil properties, types and human gut microbiota. Sci Total Environ 708: 135227, 2020

76. Reed S, Knez M, Uzan A, Stangoulis JCR, Glahn RP, Koren O and Tako E: Alterations in the Gut (Gallus gallus) microbiota following the consumption of Zinc biofortified wheat (Triticum aestivum)-based diet. J Agric Food Chem 66: 6291-6299, 2018.

77. Podany A, Rauchut J, Wu T, Kawasawa YI, Wright J, Lamendella R, Soybel DI and Kelleher SL: Excess dietary Zinc intake in neonatal mice causes oxidative stress and alters intestinal host-microbe interactions. Mol Nutr Food Res 63: e1800947, 2019.

78. Ishaq SL, Page CM, Yeoman CJ, Murphy TW, Van Emon ML and Stewart WC: Zinc AA supplementation alters yearling ram rumen bacterial communities but zinc sulfate supplementation does not. J Anim Sci 97: 687-697, 2019.

79. Zackular JP, Moore JL, Jordan AT, Juttukonda LJ, Noto MJ, Nicholson MR, Crews JD, Semler MW, Zhang Y, Ware LB, et al: Dietary zinc alters the microbiota and decreases resistance to Clostridium difficile infection. Nat Med 22: 1330-1334, 2016

80. Zhang F, Zheng W, Xue Y and Yao W: Suhuai suckling piglet hindgut microbiome-metabolome responses to different dietary copper levels. Appl Microbiol Biotechnol 103: 853-868, 2019.

81. Cheng S, Mao H, Ruan Y, Wu C, Xu Z, Hu G, Guo X, Zhang C, $\mathrm{Cao} \mathrm{H}$ and Liu P: Copper changes intestinal microbiota of the cecum and rectum in female mice by $16 \mathrm{~S}$ rRNA gene sequencing. Biol Trace Elem Res 193: 445-455, 2020.

82. Dai J, Yang X, Yuan Y, Jia Y, Liu G, Lin N, Xiao H, Zhang L and Chen J: Toxicity, gut microbiota and metabolome effects after copper exposure during early life in SD rats. Toxicology 433-434, 2020.

83. Zhang F, Zheng W, Guo R and Yao W: Effect of dietary copper level on the gut microbiota and its correlation with serum inflammatory cytokines in Sprague-Dawley rats. J Microbiol 55: 694-702, 2017.

84. Song M, Li X, Zhang X, Shi H, Vos MB, Wei X, Wang Y, Gao H, Rouchka EC, Yin X, et al: Dietary copper-fructose interactions alter gut microbial activity in male rats. Am J Physiol Gastrointest Liver Physiol 314: G119-G130, 2018.

85. Wang T, Wei X, Chen T, Wang W,Xia X, Miao J and Yin S: Studies of the mechanism of fatty liver formation in Takifugu fasciatus following copper exposure. Ecotoxicol Environ Saf 181: 353-361, 2019.

86. Meng XL, Li S, Qin CB, Zhu ZX, Hu WP, Yang LP, Lu RH, Li WJ and Nie GX: Intestinal microbiota and lipid metabolism responses in the common carp (Cyprinus carpio L.) following copper exposure. Ecotoxicol Environ Saf 160: 257-264, 2018. 
87. Yang Y, Song X, Chen A, Wang H and Chai L: Exposure to copper altered the intestinal microbiota in Chinese brown frog (Rana chensinensis). Environ Sci Pollut Res 27: 13855-13865, 2020.

88. Hemarajata $\mathrm{P}$ and Versalovic J: Effects of probiotics on gut microbiota: Mechanisms of intestinal immunomodulation and neuromodulation. Therap Adv Gastroenterol 6: 39-51, 2013.

89. Yausheva E, Sizova E, Lebedev S, Skalny A, Miroshnikov S, Plotnikov A, Khlopko Y, Gogoleva N and Cherkasov S: Influence of zinc nanoparticles on survival of worms Eisenia fetida and taxonomic diversity of the gut microflora. Environ Sci Pollut Res 23: 13245-13254, 2016.

90. Costa C, Miozzi E, Teodoro M, Briguglio G, Rapisarda V and Fenga C: New insights on 'old' toxicants in occupational toxicology (Review). Mol Med Rep 15: 3317-3322, 2017.

91. Patsiou D, Del Rio-Cubilledo C, Catarino AI, Summers S, Mohd Fahmi A, Boyle D, Fernandes TF and Henry TB: Exposure to $\mathrm{Pb}$-halide perovskite nanoparticles can deliver bioavailable $\mathrm{Pb}$ but does not alter endogenous gut microbiota in zebrafish. Sci Total Environ 715: 136941, 2020.

92. Cholewińska E, Ognik K, Fotschki B, Zduńczyk Z and Juśkiewicz J: Comparison of the effect of dietary copper nanoparticles and one copper (II) salt on the copper biodistribution and gastrointestinal and hepatic morphology and function in a rat model. PLoS One 13: e0197083, 2018.

93. Swart E, Dvorak J, Hernádi S, Goodall T, Kille P, Spurgeon D, Svendsen C and Prochazkova P: The effects of in vivo exposure to copper oxide nanoparticles on the gut microbiome, host immunity, and susceptibility to a bacterial infection in earthworms. Nanomaterials 10: 1337, 2020.

94. Sizentsov AN, Kvan OV, Miroshnikova EP, Gavrish IA, Serdaeva VA and Bykov AV: Assessment of biotoxicity of $\mathrm{Cu}$ nanoparticles with respect to probiotic strains of microorganisms and representatives of the normal flora of the intestine of broiler chickens. Environ Sci Pollut Res 25: 15765-15773, 2018.

95. Wang C, Cheng K, Zhou L, He J, Zheng X, Zhang L, Zhong X and Wang T: Evaluation of long-term toxicity of oral zinc oxide nanoparticles and zinc sulfate in mice. Biol Trace Elem Res 178: 276-282, 2017

96. Song R, Yao J, Shi Q and Wei R: Nanocomposite of Half-Fin anchovy Hydrolysates/Zinc oxide nanoparticles exhibits actual non-toxicity and regulates intestinal microbiota, Short-Chain fatty acids production and oxidative status in mice. Mar Drugs 16: 23, 2018

97. Pei X, Xiao Z, Liu L, Wang G, Tao W, Wang M, Zou J and Leng D: Effects of dietary zinc oxide nanoparticles supplementation on growth performance, zinc status, intestinal morphology, microflora population, and immune response in weaned pigs. J Sci Food Agric 99: 1366-1374, 2019.

98. Kolba N, Guo Z, Olivas FM, Mahler GJ and Tako E: Intra-amniotic administration (Gallus gallus) of $\mathrm{TiO}_{2}, \mathrm{SiO}_{2}$, and $\mathrm{ZnO}$ nanoparticles affect brush border membrane functionality and alters gut microflora populations. Food Chem Toxicol 135: 110896, 2020.
99. Vamanu E, Ene M, Biță B, Ionescu C, Crăciun L and Sârbu I: In vitro human microbiota response to exposure to silver nanoparticles biosynthesized with mushroom extract. Nutrients 10: 607, 2018

100. Yang J, Xu Y, Qian K, Zhang W, Wu D and Wang C: Effects of chromium-enriched Bacillus subtilis KT260179 supplementation on growth performance, caecal microbiology, tissue chromium level, insulin receptor expression and plasma biochemical profile of mice under heat stress. Br J Nutr 115: 774-781, 2016.

101. Yao Q, Yang H, Wang X and Wang H: Effects of hexavalent chromium on intestinal histology and microbiota in Bufo gargarizans tadpoles. Chemosphere 216: 313-323, 2019.

102. Wu G, Xiao X, Feng P, Xie F, Yu Z, Yuan W, Liu P and Li X: Gut remediation: A potential approach to reducing chromium accumulation using Lactobacillus plantarum TW1-1. Sci Rep 7: 15000, 2017

103. Chi L, Gao B, Bian X, Tu P, Ru H and Lu K: Manganese-induced sex-specific gut microbiome perturbations in C57BL/6 mice. Toxicol Appl Pharmacol 331: 142-153, 2017.

104. Wang H, Zhang S, Yang F, Xin R, Wang S, Cui D and Sun Y: The gut microbiota confers protection in the CNS against neurodegeneration induced by manganism. Biomed Pharmacother 127 $110150,2020$.

105. Zhou S, Zhang C, Xiao Q, Zhuang Y, Gu X, Yang F, Xing C, $\mathrm{Hu} \mathrm{G}$ and $\mathrm{Cao} \mathrm{H}$ : Effects of different levels of molybdenum on rumen microbiota and trace elements changes in tissues from goats. Biol Trace Elem Res 174: 85-92, 2016.

106. Del Carpio E, Hernández L, Ciangherotti C, Villalobos Coa V, Jiménez L, Lubes V and Lubes G: Vanadium: History, chemistry, interactions with $\alpha$-amino acids and potential therapeutic applications. Coord Chem Rev 372: 117-140, 2018.

107. Yuan ZH, Wang JP, Zhang KY, Ding XM, Bai SP, Zeng QF, Xuan Y and Su ZW: Effect of vanadium and tea polyphenols on intestinal morphology, microflora and Short-Chain fatty acid profile of laying hens. Biol Trace Elem Res 174: 419-427, 2016.

108. Guarneri F, Costa C, Cannavò SP, Catania S, Bua GD, Fenga C and Dugo G: Release of nickel and chromium in common foods during cooking in 18/10 (grade 316) stainless steel pots. Contact Dermatitis 76: 40-48, 2017.

109. Zhou X, Li J and Sun JL: Oral nickel changes of intestinal microflora in mice. Curr Microbiol 76: 590-596, 2019.

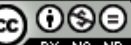

This work is licensed under a Creative Commons Attribution-NonCommercial-NoDerivatives 4.0 International (CC BY-NC-ND 4.0) License. 